\title{
Assessment of conformity of the fire safety of the building of a non-specialized car service
}

\author{
Anatoly Savelyev ${ }^{1,}$, Vladimir Shkrabak ${ }^{2}$, Mikhail Chugunov ${ }^{1}$, Svetlana Enaleeva ${ }^{1}$, and Dmitriy \\ Sengai ${ }^{1}$ \\ ${ }^{1}$ National Research Mordovian State University named after N.P. Ogarev, 430005, Republic of \\ Mordovia, Saransk, st. Bolshevik, 68, Russian Federation \\ ${ }^{2}$ St. Petersburg State Agrarian University, 196601, St. Petersburg, Pushkin, Petersburg highway, 2 , \\ Russian Federation
}

\begin{abstract}
The article is devoted to the study of the fire condition of a non-specialized car service, which is widespread mainly in agricultural areas. The assessment of compliance with the fire safety requirements of the protected object was carried out using a deterministic method and based on the calculation of fire risk. The calculation of the fire risk was carried out taking into account the absence of smoke protection at the facility and the non-compliance of the dimensions of doorways with the requirements of regulatory documents on fire safety. Calculations have shown that the value of an individual fire risk is $0,99 \cdot 10-7$ per year, i.e. does not exceed the standard value (10-6 per year), established by Federal Law No. 123-FZ. Fire safety at the protected object is ensured.
\end{abstract}

\section{Introduction}

Assessment of compliance with fire safety requirements is an initial, but one of the most important stages of ensuring fire safety of any protected object, since it involves an analysis of the actual danger to people and property from fire, and it is on this basis that specific preventive measures are developed.

Modern legislation in the field of fire safety assumes two assessment options: deterministic and risk-based.

The deterministic method of safety assessment involves the comparison of any parameters with predetermined ones, that is, those set forth in the regulatory legal acts and regulatory documents on fire safety. Since it is not possible to develop regulatory requirements that are equally justified for all protected objects, then, as a rule, they are overstated, and their implementation leads to unjustified costs.

The risk-based method, on the contrary, makes it possible, through calculations of the time of evacuation and the spread of hazardous fire factors, to simulate the process of the emergence and development of a fire of a specific object of research, to identify "weak points" in the fire safety system, and to bring the object to the required fire-fighting state with point effects.

\footnotetext{
${ }^{*}$ Corresponding author: tb280@mail.ru
} 
The above approaches are reflected in Article 6 of the Federal Law of July 22, 2008 No. 123-FZ "Technical Regulations on Fire Safety Requirements" [1] (hereinafter - the Technical Regulations), where it is stated that the fire safety of the protected object is considered to be ensured in the following cases:

1) the fire safety requirements established by the technical regulations adopted in accordance with the Federal Law "On Technical Regulation" are fully met, and the fire risk does not exceed the permissible values established by this Federal Law;

2) the fire safety requirements established by the technical regulations adopted in accordance with the Federal Law "On Technical Regulation" and fire safety regulations are fully met.

\section{Methods and materials}

The object of the study is a car service building located at the address: Republic of Mordovia, urban district of Saransk, working village Lukhovka (agricultural enterprise).

The car service building is a one-storey building with a height of $3.9 \mathrm{~m}$ and external dimensions of $24.8 \times 9.5 \mathrm{~m}$.

Building area $-235,2 \mathrm{~m} 2$, building volume $-917 \mathrm{~m} 3$.

The building has the following structural characteristics:

- foundation under the outer walls of the building: grillage on bored piles;

- brick walls, outer wall thickness $380 \mathrm{~mm}$. There are internal curtain walls and partitions;

- the roof is made of hollow-core slabs, the roof is soft;

- floors: concrete screed.

The investigated building of the car service has the following fire-technical characteristics:

- degree of fire resistance - II;

- class of fire hazard of building structures - K0;

- class of constructive fire hazard - $\mathrm{C} 0$;

- functional fire hazard class - F5.1.

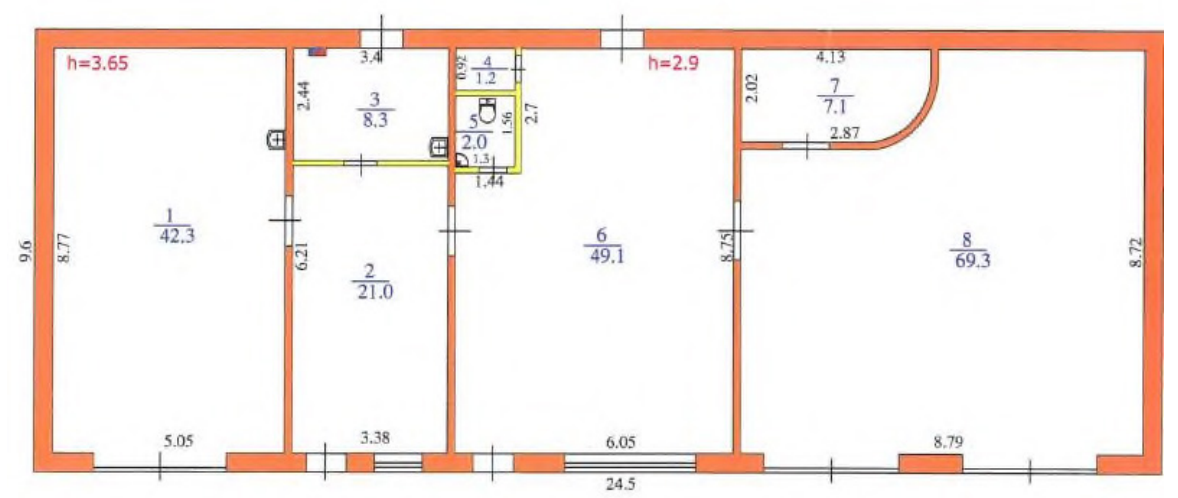

Fig. 1. Floor plan of the car service building.

The car service building includes premises for the following purposes:

- premises №№1, 2, 7, 8 - industrial premises;

- room No. 3 - changing room for car service personnel;

- room No. 4 - utility room;

- room No. 5 - a bathroom; 
- room number 6 - car service administrator's room.

Research methods:

- a method of expert assessment based on comparing the actual state of the objects of protection with the fire safety requirements of the regulatory and technical base of the Russian Federation [1-5] and the results of scientific research by domestic and foreign scientists [6-20];

- a calculation method based on the calculation of fire risk in accordance with the methodology for determining the calculated values of fire risk at production facilities (Appendix to the order of the Ministry of Emergencies of Russia dated July 10, 2009 No. 404) [4] and taking into account the provisions of fire safety regulations [2, 3]. To calculate the dynamics of hazardous fire factors (OFP), a differential (field) model of fire was used. Models of building fragments for calculating the RP were built in the graphical shell of the Pyrosim program (developer ThunderheadEngineering, USA) [5].

- modeling. As a model for calculating the evacuation time in the buildings under consideration, an individual flow model of the movement of human flows was used, which makes it possible to take into account complex behavioral factors, including the separation of human flows, as well as the individual movement of individuals or their groups. The formation of the computational grid for modeling the evacuation processes was carried out in a trial version of the Pathfinder 2018.2 $\times 64$ program (developed by ThunderheadEngineering, USA) [5].

\section{Research results and discussion}

The main technological process in the building of the car service is the maintenance and repair of diesel vehicles.

In room No. 1, passenger cars are being repaired on a hydraulic lift, equipment and tools are placed in the room on metal racks.

In room 2, tire fitting operations are carried out on tire changers, tools are placed on metal racks.

Room 7 houses a compressor unit for generating compressed air used for technological purposes of a car service.

In room No. 8, a car repair and wash station was organized. Repairs are carried out without the use of a hydraulic lift. The room houses equipment and tools on metal racks.

The operating mode of the car service is from 8 to 18 hours without breaks and days off.

In the premises of the car service building during the work shift, there is personnel, the time of presence of which, depending on the position, is given in table 1, the operating mode is given in table 2 .

In accordance with clause 4.2 of Table A.1 SP 5.13130.2009 and clause 6.3 VSN 01-89, the car service building under study is subject to protection by an automatic fire alarm (AUPS).

The car service building is equipped with an automatic fire alarm system based on Granit-5 and UPKOP 135-1-2P (explosion-proof) control and monitoring devices. Smoke detectors IP 212-189, explosion-proof thermal fire detectors IP 103-5 / 1-A3 IB were used as fire detectors for detecting dangerous fire factors at the facility. To turn on the fire alarm system in manual mode, manual fire detectors of the IP 513-10 type and explosion-proof IPR-513-2 (AGAT IB) are used. The formation of the "Fire" signal by the fire alarm installation occurs when any one automatic fire detector is triggered, or when any manual fire detector is turned on. 
Table 1. Time spent by staff in a shift in the premises of the car service building, depending on positions.

\begin{tabular}{|c|c|c|}
\hline Position & Per day & $\begin{array}{l}\text { Number of } \\
\text { hours }\end{array}$ \\
\hline \multicolumn{3}{|c|}{ Room No. 1 (lift room) } \\
\hline Master & 1 person & 7,5 \\
\hline Locksmith-repairman №1 & 1 person & 11 \\
\hline \multicolumn{3}{|c|}{ Room No. 2 (tire fitting room) } \\
\hline Locksmith-repairman №2 & 1 person & 5 \\
\hline \multicolumn{3}{|c|}{ Room No. 3 (staff locker room) } \\
\hline Master & 1 person & 0,5 \\
\hline Locksmith-repairman №1 & 1 person & 0,5 \\
\hline Locksmith-repairman №2 & 1 person & 0,5 \\
\hline \multicolumn{3}{|c|}{ Room No. 6 (car service administrator's room) } \\
\hline Administrator & 1 person & 11 \\
\hline \multicolumn{3}{|c|}{ Room No. 7 (compressor room) } \\
\hline Master & 1 person & 0,5 \\
\hline \multicolumn{3}{|c|}{ Room No. 8 (repair and washing station) } \\
\hline Locksmith-repairman №2 & 1 person & 3 \\
\hline
\end{tabular}

Room No. 6 (car service administrator's room), in addition to the administrator, can accommodate up to 10 visitors.

Table 2. The mode of work of personnel in the car service, depending on positions.

\begin{tabular}{|l|l|}
\hline \multicolumn{1}{|c|}{ Position } & \multicolumn{1}{c|}{ Working hours } \\
\hline Administrator & 11 hours (2 days in two days) \\
\hline Master & 8 hours (5 days a week) \\
\hline Locksmith-repairman №1 & 11 hours (2 days in two days) \\
\hline Locksmith-repairman №2 & 8 hours (5 days a week) \\
\hline
\end{tabular}

In accordance with clause 17 of Table 2 of SP 3.13130.2009, a one-story building of a car workshop of category B for fire hazard is subject to protection by a fire warning and evacuation control system (SOUE) of at least type 1 .

The system for alerting people and managing the evacuation of people in case of fire for the investigated building of the car service was adopted of the 2nd type, which provides for the submission of sound alerts using Mayak-12-3M and Shmel-12 sirens, as well as the presence of "Exit" LUX-12 MS and explosion-proof light boards "Exit" included in the package UPKOP135-1-2P.

In the investigated building of the car service, in accordance with clause 7.2 "e" of SP 7.13130 .2013 [3], industrial premises with permanent workplaces of category B2 for fire hazard are subject to protection by exhaust smoke ventilation systems, i.e. smoke protection (PDZ). 
However, there is no PDZ in the investigated car service building.

The premises of the car service building under study are equipped with evacuation exits in accordance with the requirements of Article 89 of the Federal Law No. 123-FZ [1], namely:

- from room 1 (lift room) directly outside through the gate;

- from room 2 (tire fitting room) directly outside;

- from room No. 3 (changing room for car service personnel) directly outside;

- from premises No. 4 and No. 5 (utility room and bathroom) to adjacent room No. 6 (car service administrator's room), from which an evacuation exit is provided directly outside;

- from room 6 (car service administrator's room) directly outside;

- from room No. 7 (compressor room) to an adjacent room No. 8 (repair and washing station), from which an evacuation exit is provided directly outside;

- from room 8 (repair and wash station) directly outside.

Rooms No. 1 and No. 2, rooms No. 2 and No. 3, rooms No. 2 and No. 6, as well as rooms No. 6 and No. 8 have communication with each other through the doorway, which is considered as an emergency exit leading from one room to the next, provided with an evacuation exit directly outside.

Evacuation from rooms No. 1 and No. 8 is provided directly outside through the gate.

The gates in the car service building are made up-and-down with the ability to manually open them from the inside and lock them open.

In accordance with clause 4.2.5 of SP 1.13130.2009 [3], the clear height of emergency exits must be at least $1.9 \mathrm{~m}$, width at least $0.8 \mathrm{~m}$.

During the inspection, it was found that in the investigated building of the car service there are emergency exits, the width of which in the light is less than $0.8 \mathrm{~m}$, but not less than $0.7 \mathrm{~m}$.

Thus, if the deterministic method of object assessment is applied, the car service building does not meet fire safety requirements. It is necessary to install an expensive smoke protection system, as well as to bring the dimensions of emergency exits to a width of at least $0.8 \mathrm{~m}$.

We will assess the conformity of the car service building based on the calculation of fire risk. At the same time, the assessment of the individual fire risk will be carried out taking into account the absence of PDZ in the building and according to the actual state (size) of emergency exits.

In accordance with the initial data provided by the Customer, the protected object is an object of the functional fire hazard class $\Phi 5.1$ - an industrial building with auxiliary premises.

In accordance with the class of functional fire hazard of the considered object of protection, the provisions of the Methodology for determining design values at production facilities, approved by order of the Ministry of Emergency Situations of Russia dated 10.07.2009 No. 404 [4], will apply to it, taking into account the changes that have come into force.

In accordance with the concept of fire risk assessment for production facilities, the technological scheme of the car service building was conditionally divided into technological sections (production premises, premises for domestic and public purposes).

The situation is considered as a fire hazard - a fire associated with the combustion of a fire load in the form of solid combustible materials or spills of combustible liquids. In turn, spills of flammable liquid can form as a result of equipment depressurization, and after the appearance of an ignition source, a fire occurs.

When carrying out the calculations, the field method of mathematical modeling was used. The program Fire Dynamics Simulator (hereinafter referred to as FDS) produced by 
the National Institute of Standards and Technology (NIST) [5], USA, was used as a program that implements a field model and allows the calculation of fire dynamics.

As a model for calculating the time of evacuation in the building under consideration, an individual flow model of the movement of human flows was used, which makes it possible to take into account complex behavioral factors, including the separation of human flows, as well as the individual movement of individuals or their groups.

The formation of the computational grid for modeling the evacuation processes was carried out in the Pathfinder program (developed by Thunderhead Engineering, USA) [5], which implements an individual flow model.

For the considered object of protection, characteristic places of occurrence of fires can be the following:

- section No. 1: production room No. 1 (lift room);

- section No. 2: production room No. 8 (repair and washing station);

- section No. 3: production room No. 2 (tire fitting room);

- section 4: room 3 (changing room for car service personnel);

- section 5: room 6 (car service administrator's room);

- section 6: room 7 (compressor room).

Taking into account the analysis of the fire hazard of an object, similar objects, including fires on them, it can be concluded that most often fires occur either in household premises, including as a result of emergency fire-hazardous modes of operation in power grids or during careless handling of fire, or in industrial premises where maintenance or repair work is carried out on a car, which themselves contain potential sources of ignition, and in addition, repair work is accompanied by the appearance of potential sources of ignition in the presence of a combustible environment.

At the same time, it should be noted that the dynamics of fire growth for domestic premises, as a rule, is lower than for cars. In addition, the fire load of vehicles is characterized by a higher fire hazard.

In this regard, a fire in the elevator room was chosen as the most unfavorable fire hazard scenario. The model view for calculating hazardous fire factors is shown in Figure 2.

In the scenario under consideration, the first blocking of the evacuation exit occurred from room No. 1 (lift room) to room No. 2 (tire fitting room) due to the loss of visibility at the time $56.8 \mathrm{~s}$.

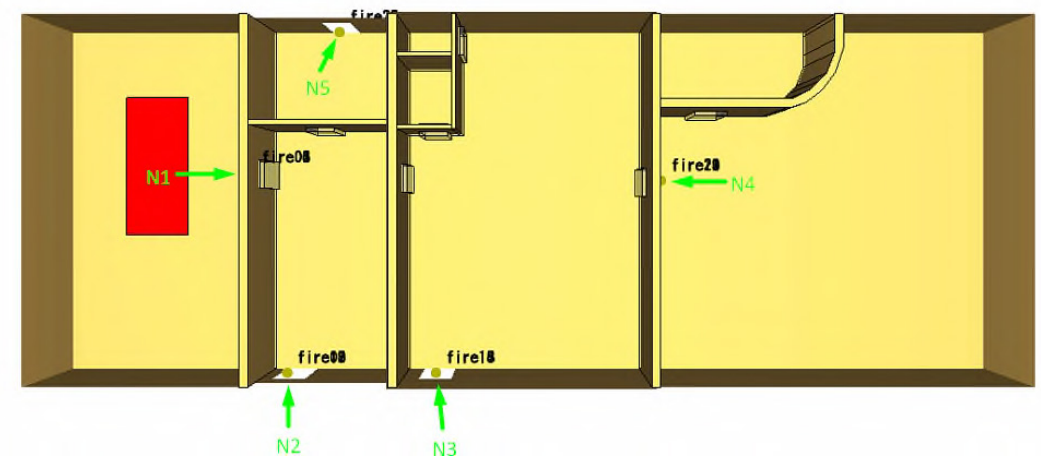

Fig. 2. View of the model for calculating relative permeability.

The fire center is highlighted in red, the arrow shows the RPM measurement points (arrow No. 1: sensors No. 0106 - exit from room No. 1 (elevator room); arrow No. 2: sensors No. No. 0712 - exit from room No. 2 (tire fitting room) ); arrow No. 3: sensors No. 1318 - exit from room No. 6 (car service administrator's room); arrow No. 4: sensors No. 
No. 1924 - exit from room No. 8 (repair and washing station); arrow No. 5: sensors №№ 2530 - exit from room №3 (changing room for car service personnel).

The layout of people during evacuation is shown in Figure 3.

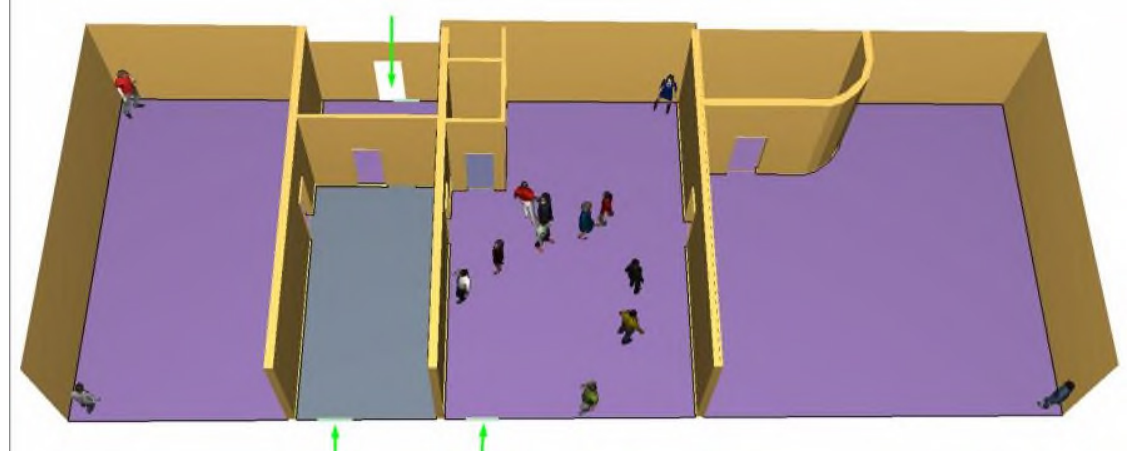

Fig. 3. Layout of people in the premises of the building.

The arrows show the evacuation exits from the building.

The evacuation time in the considered fire scenario was taken according to the longest exit time from the car service building and amounted to $42.2 \mathrm{~s}$ ( $0.70 \mathrm{~min})$.

Statistical data on the frequency of fire in various industrial buildings are given in the Manual [14], and in this article - in tables 3 and 4.

Table 3. Statistical data on the frequency of fire in various industrial buildings.

\begin{tabular}{|l|c|}
\hline \multicolumn{1}{|c|}{ Object } & $\begin{array}{c}\text { Frequency } \\
\text { fire breakout } \\
\left(\mathbf{1 0}^{-5} \cdot \mathbf{m}^{-2} \cdot \text { year-1) }\right.\end{array}$ \\
\hline Power plants & 2,2 \\
\hline Warehouses of chemical products & 1,2 \\
\hline Warehouses for multi-product products & 9,0 \\
\hline Tool-mechanical shops & 0,6 \\
\hline $\begin{array}{l}\text { Workshops for the processing of synthetic rubber and artificial } \\
\text { fibers }\end{array}$ & 2,7 \\
\hline Foundry and smelting shops & 1,9 \\
\hline Workshops for processing meat and fish products & 1,5 \\
\hline Workshops for hot rolling of metals & 1,9 \\
\hline Textile production & 1,5 \\
\hline Administrative production buildings & 1,2 \\
\hline
\end{tabular}

The dependence of the frequency of fire in a building on the area of the building may not be linear. The frequency of a fire in a building (room) can be determined by the formula:

$$
Q=a F^{b},
$$

wherte $\mathrm{a}, \mathrm{b}$ - constants determined for various buildings according to the table below, $\mathrm{F}$ is the area of the building (room) of the production facility, $\mathrm{m}^{2}$. The application of this formula is recommended when the area of objects is more than $1000 \mathrm{~m}^{2}$.

Taking into account the provisions (paragraph 34) of the Methodology [4], the estimated frequency of fire occurrence is taken to be equal to the total frequency of realization of all possible fire scenarios in the building.

The frequency of fires for a car service building, in which fire hazard scenarios are considered, is taken as for a vehicle service building $\left(\mathrm{a}=1,2 \cdot 10^{-4} ; \mathrm{b}=0,86\right)$ : 


$$
\begin{aligned}
Q=a F^{b} & =1,2 \cdot 10^{-4} \cdot 200,3^{0,86}= \\
& =1,1 \cdot 10-2 \text { per year. }
\end{aligned}
$$

When calculating the potential fire risk, we proceeded from the following.

Table 4. Statistical data on the frequency of fire in various industrial buildings.

\begin{tabular}{|l|l|l|}
\hline \multicolumn{1}{|c|}{ Characteristics of the building } & \multicolumn{1}{|c|}{ a } & \multicolumn{1}{|c|}{ b } \\
\hline Buildings of the food, tobacco industry & 0,0011 & 0,6 \\
\hline $\begin{array}{l}\text { Recycling of combustible substances, chemical } \\
\text { industry }\end{array}$ & 0,0069 & 0,46 \\
\hline Placement of electrical equipment & 0,0061 & 0,59 \\
\hline Vehicle maintenance & 0,00012 & 0,86 \\
\hline Textile industry & 0,0075 & 0,35 \\
\hline Printing enterprises, publishing & 0,0007 & 0,91 \\
\hline Administrative buildings of production facilities & 0,00006 & 0,9 \\
\hline Other types of production facilities & 0,0084 & 0,41 \\
\hline
\end{tabular}

Probability DSP of effective operation of the technical means of the system smoke protection (SP) taken equal to zero, since this system is required at the facility, but the facility is not equipped with this system.

Probability DAFES of efficient operation of technical means automatic fire extinguishing system (AFES) taken equal to zero, since the above system is not required at the facility and the facility is not equipped with this system.

Probability effective operation of technical means of fire protection, namely AFES and SOUE is taken equal to DAFES $=0,8$ and DSOUE $=0,8$, since these systems are installed at the facility, comply with the requirements of fire safety regulations and are maintained.

Probability of evacuation by evacuation routes PE.R. taken equal to 0,999 , since the evacuation time of people is less than the required evacuation time.

Probability of evacuation through emergency or other exits PO.R. taken equal to 0.03 , since such outputs are available.

$$
P_{E}=1-\left(1-P_{E . R}\right) \cdot\left(1-P_{O . R .} 0\right)=1-(1-0,999) \cdot(1-0,03)=0,99903
$$

The potential fire risk for people in the car service building, taking into account the possibility of a fire, will be:

$$
\begin{gathered}
P=1,1 \cdot 10^{-2} \cdot(1-0,99903) \cdot(1-0) \cdot(1-0) . \\
*(1-0,8) \cdot(1-0,8)=0,43 \cdot 10-6 .
\end{gathered}
$$

Since the premises of the car service building are structurally designed in such a way that in the event of a fire in any of the premises, the potential fire risk is summed up, the individual fire risk will be determined by the total potential risk, taking into account the longest time spent by an individual in any of the premises.

It was found that the longest staff work time is 11 hours with the operating mode "two days after two days".

Thus, under the current operating mode, the probability of the presence of an employee of the enterprise (for positions with the above operating mode) will be: 


$$
P_{\text {personnel }}=\frac{1}{2} \frac{11}{24}=0,2292 \text { per year } .
$$

The individual fire risk for people in the car service building will be:

$$
R=P_{\text {personnel }} \cdot P=0,2292 \times 0,43 \cdot 10^{-6}=0,99 \cdot 10^{-7} .
$$

\section{Conclusion}

Thus, the value of the individual fire risk is $0,99 \cdot 10-7$ per year, i.e. does not exceed the standard value (10-6 per year), established by Federal Law No. 123-FZ [1].

As already noted, the calculation of fire risk was carried out taking into account the absence of smoke protection at the facility and the non-compliance of the dimensions of doorways with the requirements of fire safety regulations. Calculations have shown that safety is ensured with these inconsistencies.

When implementing a risk-based approach for the facility to comply with fire safety requirements, in addition to the normative value of fire risk at the protected facility, the fire safety requirements established by the technical regulations adopted in accordance with Federal Law No. 184-FZ must be met in full.

The object of research is the object of completed construction. In this regard, the technical regulations adopted in accordance with Federal Law No. 184-FZ, which set out the fire safety requirements for the research object, are Federal Law No. 123-FZ and Federal Law No. 384-FZ.

The conducted research has established that the fire safety requirements stipulated by the Federal Law No. 384-FZ and the Federal Law No. 123-FZ [3] were met in full at the investigated facility.

Since the magnitude of the fire risk does not exceed the permissible value 10-6 per year, established by Art. 93 of Federal Law No. 123-FZ, this allows us to conclude that in accordance with paragraph 1 of Part 2 of Art. 6 of Federal Law No. 123-FZ, the car service building located at the address: Republic of Mordovia, urban district of Saransk, working village Lukhovka, Oktyabrskaya street, house No. 17 "D", meets fire safety requirements.

As a result of this work, it was shown that when assessing an object on the basis of fire risk, the protected object meets fire safety requirements, including in the absence of smoke protection and the actual size of evacuation exits is less than required.

This allows you to optimize the cost of ensuring fire safety at the facility.

\section{References}

1. Federal Law of December 27, 2002 No. 184-FZ "On Technical Regulation"

2. SP 7.13130.2013. Heating, ventilation and air conditioning. Fire safety requirements

3. SP 1.13130.2009. Fire protection systems. Evacuation routes and exits

4. Order of the Ministry of Emergency Situations of the Russian Federation dated July 10, 2009 No. 404 "On approval of the methodology for determining the design values at production facilities."

5. Pathfinder User Manual 2018. Thunderhead Engineering. Manhattan.

6. M Ahrens, Fires in Industrial Trucks and Forklifts ", Statistical Report of the National Fire Protection Association, USA, Industrial Loadersand ForkliftFires. National Fire Protection Association (2009)

7. NFPA 204 Standard for Smoke and Heat Venting (2012 Edition) 
8. H. Ingason, R. Hammarstrom, Fire test with a front wheel loader rubber tyre, SP Report 2010:64, SP Technical Research Institute of Sweden

9. NIST Special Publication 1018: Sixth Edition. Fire Dynamics Simulator Technical Reference Guide, Volume 1: Mathematical Model. - National Institute of Standards and Technology, VTT Technical Research Centre of Finland (2013)

10. NIST Special Publication 1019: Sixth Edition. Fire Dynamics Simulator User's Guide. - National Institute of Standards and Technology, VTT Technical Research Centre of Finland (2013)

11. Carvalho A.C., Carvalho A., Martins H., Marques C., Rocha A., Borrego C., et al., Fire weather risk assessment under climate change using a dynamical downscaling approach, Environmental Modelling \& Software 26(9), 1123-33 (2011)

12. Herawati H., Santoso H., Tropical forest susceptibility to and risk of fire under changing climate: A review of fire nature, policy and institutions in Indonesia, Forest Policy and Economics 13(4), 227-33 (2011)

13. Grayson R, Kinilakodi H, Kecojevic V., Pilot sample risk analysis for underground coal mine fires and explosions using MSHA citation data, Safety Science 47(10), 137178 (2009)

14. Alhussan K., Thermal Radiation of Explosion: Estimations of Risk of Thermal Defeat of People and Occurrence of Fires. Procedia Engineering 61(0), 185-91 (2013)

15. Paz S., Carmel Y., Jahshan F., Shoshany M., Post-fire analysis of pre-fire mapping of fire-risk: A recent case study from Mt. Carmel (Israel), Forest Ecology and Management 262(7), 1184-88 (2011)

16. Shinneman D.J., Palik B.J., Cornett M.W., Can landscape-level ecological restoration influence firerisk? A spatially-explicit assessment of a northern temperate-southern boreal forest landscape, Forest Ecology and Management 274(0), 126-35 (2012)

17. Castillo S.M.E., The identification and assessment of areas at risk of forest fire using fuzzy methodology, Applied Geography 35(1-2), 199-207 (2012)

18. Maeda E.E., Arcoverde G.F.B., Pellikka P.K.E., Shimabukuro Y.E., Fire risk assessment in the Brazilian Amazon using MODIS imagery and change vector analysis, Applied Geography 31(1), 76-84 (2011)

19. He Y., Probabilistic Fire-risk-assessment Function and Its Application in Fire Resistance Design, Procedia Engineering 62(0), 130-9 (2013)

20. Gałaj J., Jaskółowski W., Konecki M., Tofiło P., Tuśnio N., Interactive Modular Platform for Fire Risk Assessment of Buildings as a Supporting Tool for Buildings and Infrastructures Design, Procedia Engineering 57(0), 310-9 (2013) 